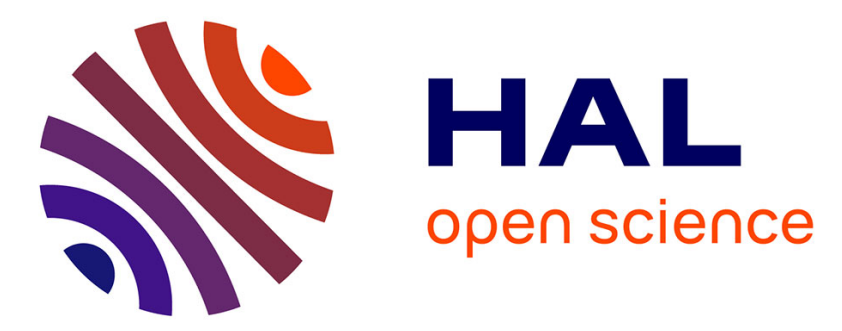

\title{
Bumblebees develop more efficient traplines than honey bees
}

\author{
Alexis Buatois, Thibault Dubois, Lihoreau Mathieu
}

\section{To cite this version:}

Alexis Buatois, Thibault Dubois, Lihoreau Mathieu. Bumblebees develop more efficient traplines than honey bees. 2021. hal-03094384v2

\section{HAL Id: hal-03094384 \\ https://hal.science/hal-03094384v2}

Preprint submitted on 4 Jan 2021

HAL is a multi-disciplinary open access archive for the deposit and dissemination of scientific research documents, whether they are published or not. The documents may come from teaching and research institutions in France or abroad, or from public or private research centers.
L'archive ouverte pluridisciplinaire HAL, est destinée au dépôt et à la diffusion de documents scientifiques de niveau recherche, publiés ou non, émanant des établissements d'enseignement et de recherche français ou étrangers, des laboratoires publics ou privés. 


\section{Bumblebees develop more efficient traplines than honey bees}

3 Alexis Buatois $^{1 *}$, Thibault Dubois ${ }^{1,2}$, Mathieu Lihoreau ${ }^{1}$

$5 \quad{ }^{1}$ Research Center on Animal Cognition (CRCA), Research Center for Integrative Biology (CBI);

6 CNRS, University Paul Sabatier, Toulouse, France.

$7 \quad{ }^{2}$ Department of Biological Sciences, Macquarie University, NSW, Australia

8 *correspondence: buatoisalexis@gmail.com

\section{Abstract}

12 Central place foraging pollinators, such as bees, tend to learn multi-destination routes (traplines)

13 to efficiently visit known feeding locations and return to their nest. To what extent these routing

14 behaviours are shared across species is unknown. Here we ran laboratory experiments to compare

15 trapline formation and efficiency by foragers of two social bee species that differ in their collective

16 foraging strategies: the solo foraging bumblebee Bombus terrestris and the mass foraging honey

17 bee Apis mellifera. In a simple routing task with four artificial flowers, both bumblebees and honey

18 bees developed a stable route, although honey bees were slower and less efficient to do so. In a

19 more complex routing task with six flowers, only bumblebees developed a stable route. Honey bees

20 took a longer time to discover all flowers and never integrated them in a single route. Simulations

21 of a model of trapline formation show that these inter-specific differences can be replicated by

22 adjusting the strength of a single learning parameter. Comparing bumblebees and honey bees in

23 the same experimental conditions thus revealed key differences in their spatial foraging strategies,

24 potentially driven by social constraints.

\section{Keywords}

27 Honeybees; bumble bees; trapline foraging; navigation; comparative cognition. 


\section{Introduction}

30 Central place foraging pollinators often develop multi-destination routes (or traplines) to efficiently

31 exploit patchily distributed feeding sites (Thomson et al. 1996). Trapline foraging is widespread in 32 nectar feeding insects (orchid bees: Janzen 1971; bumblebees: Thomson et al. 1997; honey bees:

33 Buatois and Lihoreau 2016; butterflies: Gilbert and Singer 1975) but also in birds (hummingbirds:

34 Tello-Ramos et al. 2015) and mammals (bats: Lemke 1984; opposums: Wooller et al 1999). This

35 routing behaviour is thought to optimize the exploitation of plants resources, by adjusting the

36 timing of nectar collection and deterring competitors (Possingham 1989; Ohashi and Thomson 37 2005). bumblebees given an access to a small number of flowers for several hours often find and use the shortest sequence to visit all flowers once and return to the nest (Ohashi et al. 2007; Lihoreau et al. 2010, 2012a). Analyses of the flight paths of bumblebees between visiting flowers, show that insects also tend to optimize travel distances (Lihoreau et al. 2012b; Woodgate et al. 2017). Trapline formation can be modelled using an iterative improvement heuristic of vector navigation replicating trial-and-error learning by bees (Lihoreau et al. 2012b; Reynolds et al. 2013). In this approach, the bumblebee compares the net length of all the route segments (i.e. straight movements between two flowers or between a flower and the colony nest) composing the route it has just experienced, and increases its probability to reuse these segments in future if the new route is shorter (or of the same length) than the shortest route experienced before.

Recently, honey bees were also reported to be capable of developing traplines between four artificial flowers (Buatois and Lihoreau 2016). The indirect comparison of the foraging patterns of bumblebees and honey bees, using network statistics on data obtained in different studies, suggests

53 that honey bees develop less efficient routes and are less faithful to these routes than bumblebees

54 (Pasquaretta et al. 2017). This may be explained by major differences in the social ecology of these

55 bees. Bumblebees, as solo foragers, primarily rely on the acquisition of individual information to locate and exploit plant resources (Dornhaus and Chittka 1999). By contrast, honey bee are mass foragers and use social information to collectively exploit profitable food resources (e.g. they use the waggle dance for recruiting nestmates to resources $100 \mathrm{~m}$ away from the nest, von Frisch 1967). 
60 (Buatois and Lihoreau 2016). Further understanding these behavioural differences could have

61 considerable implications for assessing the impact of foraging strategies and social structure on the

62 evolution of cognition in two major pollinators and model species in for insect behaviour (Farris

63 2016; Traniello et al. 2019). Such approach requires to study the animals in strictly identical setups

64 and make quantitative comparisons of their performances (Chittka et al. 2012).

65 Here, we tested the hypothesis that honey bees have poorer abilities to develop foraging 66 routes than bumblebees, by comparing the spatial patterns of individuals of both species in the

67 same arrays of artificial flowers in an indoor flight room. Since the number of possible routes to

68 visit each flower once and return to the nest increases factorially with the numbers of flowers to 69 visit (Lihoreau et al. 2013), we tested the influence of task complexity by observing bumblebees 70 and honey bees foraging in arrays of four flowers (24 possible routes) and six flowers (720 possible 71 routes). We then compared the performances of foragers of both species with numerical simulations 72 of a model of trapline formation.

\section{Materials and methods}

\section{Bees}

76 We used a small colony (a queen and ca. 2000 workers) of honey bees (Apis mellifera, Buckfast)

77 originating from the experimental apiary of the University Paul Sabatier - Toulouse III (France).

78 We used a normal size colony (a queen and ca. 200 workers) of bumblebees (Bombus terrestris)

79 from Biobest (Belgium). Both honey bee and bumblebee hives were equipped with a transparent

80 entrance tube fitted with gates to precisely control the traffic of foragers. Colonies were provided

81 ad libitum defrosted pollen directly into the hives. Workers collected sucrose solution (40\% w/w 82 in water) from artificial flowers in the flight room.

\section{Flight room}

85 We conducted the experiments in an indoor flight room (length: $7 \mathrm{~m}$, width: $5 \mathrm{~m}$, height: $3 \mathrm{~m}$; 86 Fig.S1A) equipped with 12 wide spectrum LED lights (6500K, Phillips, The Netherlands) 87 replicating natural sunlight and daily photocycle (15h Light/ 9h Dark). Four posters uniquely 88 characterized by a bicolored pattern were placed on the room walls to provide $2 \mathrm{D}$ visual landmarks 89 to the bees (Fig.S2). 


\section{Artificial flowers}

92 Each flower consisted of a $6 \mathrm{~cm}$ diameter blue landing platform sitting on a $10 \mathrm{~cm}$ high transparent

93 plastic cylinder. The cylinder was attached to a clamp stand $50 \mathrm{~cm}$ above ground (Fig.S1B, Buatois

94 and Lihoreau 2016). A yellow mark in the middle of the landing platform indicated the location of 95 a controlled volume of sucrose solution (40\% w/w, range: $\min 20 \mu \mathrm{l}$ - max $140 \mu \mathrm{l})$ dispensed using 96 an electronic micropipette (Brand Handystep 705000, Germany).

\section{Flower arrays}

99 Bees were tested either in a four-flowers array or in a six-flowers array (see flower coordinates in

100 Fig.S1A). We used these two arrays to provide bees with spatial tasks of increasing complexity. In

101 the four-flowers arrays there was 24 possible sequences to visit all flowers once starting and ending 102 at the colony nest entrance (including the two optimal sequences F1-F2-F3-F4 or F4-F3-F2-F1; 103 Figs 1 and S1A). In the six-flowers array, there were 720 possible sequences (including the two 104 optimal sequences: F1-F2-F3-F4-F5-F6 or F6-F5-F4-F3-F2-F1; Figs 3 and S1B). Flower arrays 105 were generated using a computer program (R code available in Text S1) designed to maximize the 106 discrepancy between the two optimal flower visitation sequences minimizing travel distance to 107 visit all flowers (e.g. four-flowers array: F1-F2-F3-F4 or F4-F3-F2-F1) and the flower visitation 108 sequence linking all unvisited nearest neighbour flowers (e.g. four-flowers array: F1-F4-F5-F2) 109 given the dimensions of our flight room. The distance between neighbour flowers ranged from 1.48 $110 \mathrm{~m}$ to $4.19 \mathrm{~m}$ in the four-flowers array, and $1.13 \mathrm{~m}$ to $4.22 \mathrm{~m}$ in the six-flowers array. Since bee 111 workers detect visual targets from a background subtending a minimum visual angle between ca. $1123^{\circ}$ (B. terrestris; Dyer et al. 2008) and 5 (A. mellifera; Giurfa et al. 1996; Kapustjansky et al. 113 2010), we assumed that bees could visually detect the $50 \mathrm{~cm}$ tall flowers from any location in the 114 flight room. The small spatial scale of the experimental arrays (i.e. the maximum length between 115 a flower and the nest was $6.41 \mathrm{~m}$ ) prevented any dance communication between the honey bees 116 (von Frisch 1967).

118 Traplining experiments

119 We pre-trained the bees collectively on an artificial flower delivering ad libitum sucrose solution 120 (3.5cm petri dish full of sucrose solution on top of blue landing platform, $40 \% \mathrm{w} / \mathrm{w}$ ) and marked 
121 them with acrylic paint on the thorax for individual identification (von Frisch 1967). Once a bee

122 made regular foraging bouts (foraging trips starting and ending at the colony hive entrance), we

123 measured its nectar crop capacity (average \pm SE; bumblebees: $120 \pm 20 \mu \mathrm{L}, \mathrm{N}=20$; honey bees:

$12442.3 \pm 10 \mu \mathrm{L}, \mathrm{N}=19$ ) by estimating the average total amount of sucrose solution collected by that

125 bee over three foraging bouts (Lihoreau et al. 2010). We then tested the bee either for 30

126 consecutive foraging bouts in the four-flowers array or 50 consecutive foraging bouts in the six-

127 flowers array. The number of trials differed between the two arrays based on previous observations

128 that bees require more time to develop routes between six flowers than in a more simple array of

129 four flowers (Lihoreau et al. 2010, 2012a). Each flower provided either 1/4th (four-flowers array)

130 or 1/6th (six-flowers array) of the bee's nectar crop capacity and was refilled with sucrose solution

131 between each foraging bout. Between testing different bees, flowers were cleaned with ethanol

$132(70 \% \mathrm{w} / \mathrm{w})$ to remove chemical cues that could influence the next foragers (Giurfa and Núñez

133 1992; Pearce et al. 2017). In total, 10 bumblebees and 10 honey bees were tested in the four-flowers

134 array, and another 10 bumblebees and 9 honey bees were tested in the six-flowers array $(\mathrm{N}=39$

135 bees in total). All data were collected by an experimenter using the software Ethom (Taiwanica

136 2000). For each foraging bout of each bee, we recorded the time when the bee left the hive, each

137 time it landed on a flower, took off, and the time when it returned to the nest.

\section{Modeling}

140 We compared the observational data to numerical simulations of an agent-based model of trapline 141 development (see details in Lihoreau et al. 2012b; Reynolds et al., 2013). Briefly, in the model the 142 agent (bee) forages according to the following set of rules: (1) the bee has a probability of using 143 movement vectors joining two targets (two flowers, or the nest and a flower); (2) the initial 144 probability of using a vector depends on the distance between the two targets (probabilities are 145 inversely proportional to the squared distance between targets and are normalized with respect to 146 all targets); (3) the bee computes the net length of the route travelled by summing the lengths of all 147 vectors comprising the route; (4) if the route passed through all the flowers at least once (thus 148 filling the nectar crop capacity of the bee), the bee compares the net length of the current route to 149 the net length of the shortest route experienced so far that passes through all the flowers; (5) if the 150 length of the new route is inferior or equal, the probabilities of using the vectors comprising this 151 new route in the next foraging bout are multiplied by a common factor (learning factor, lf) and all 
152 probabilities are rescaled with respect to all flowers so that they sum to unity. (6) If the bee returns

153 to the nest, the foraging bout ends no matter the number of flowers visited. Revisits to flowers are

154 not taken into account in the learning process, so that vectors including revisits to any flower are 155 not reinforced through learning. We explored outputs of the model with values of learning factors

156 ranging between 1 and 2, as suggested by Reynolds et al. (2013) for simulations at small spatial 157 scales. A learning factor of 1.0 replicates situations where the bee does not learn (i.e. null model).

158 Increasing values of the learning factor should lead bees to converge faster towards a stable 159 optimized trapline. For each value of learning factor, we simulated 1000 times the execution of 30 160 foraging bouts (for the four-flowers array) or 50 foraging bouts (for the six-flowers array).

161

\section{Data analyses}

163 We ran all analyses in $\mathrm{R}$ (R Development Core Team 2016).

\section{Behavioural data}

166 From the behavioural data, we extracted raw sequences of flower visitation (see Table S1-4). We 167 calculated the total duration of a foraging bout (time between departure and arrival at the hive), the 168 number of different flowers visited per foraging bout, the number of foraging bouts for which each 169 flower has been visited during the whole experiment, and the number of immediate revisits to the 170 same flowers per foraging bout (no other flower visited in between). A bee was considered to use 171 a route (i.e., flower visitation sequence without immediate and non-immediate revisits) 172 significantly more often than expected by chance if the route was used at least four times in the 173 four-flowers array (24 possible routes in total), and two times in the six-flowers array (720 possible 174 routes in total). The 'primary route' for one bee was its most used one according to these previous 175 rules (Lihoreau et al. 2010).

176 We assessed route optimality using an index of route quality (i.e., the squared number of 177 different flowers visited divided by the length of the route). The index of each route was divided 178 by the route quality of the optimal route, so that its value varied between 0 (very poor route quality) 179 and 1 (quality equal to the optimal route). We assessed route repeatability using a determinism 180 index (DET; see details in Ayers et al., 2015). This index is set between 0 (no repeated visitation 181 patterns in a visitation sequence) and 1 (complete traplining). We computed the DET for groups of 
10 successive foraging bouts, using a minimum length of recurrence of 4 and without considering perpendicular diagonals.

We compared the behavioural performance (number of flowers visited, number of 185 immediate revisits and time flying per foraging bout) of bumblebees and honey bees using 186 generalized linear mixed models (GLMMs) with foraging bouts within bee identity as a random 187 factor using lme4 package (Bates et al., 2014). Regarding the first trial each flower was visited, as 188 well as the percentage of bout each flower was visited, the comparison between species within each individual flower was done using a Wilcoxon Rank-test for independent data.

\section{Model simulations}

192 For each model simulation (set of 1000 stimulations), we extracted the visitation sequences, the 193 number of different flowers visited per foraging bout, the travel distance for each foraging bout,

194 the route quality and the DET. We compared the behavioural data to the model simulations using 195 GLMMs to check for significant differences in route quality and DET. We used the statistical 196 differences in slopes (seen in the model as the interaction between the bout and treatment effects) to discriminate the experimental data and the models. A similar statistical comparison for treatment 198 effect alone can be found in the supplementary materials (Table S5).

\section{Results}

\section{Four-flowers array}

202 We first compared the flower visitation sequences of bumblebees and honey bees in an array of

203 four flowers (Fig.1A). Bumblebees and honey bees similarly increased the number of different

204 flowers visited per foraging bout as they gained experience with the array (Fig.1B; Poisson 205 GLMM; species, est=0.02, $\mathrm{z}_{595}=0.19, \mathrm{p}=0.85$; foraging bout: est $=0.007, \mathrm{z}_{595}=2.12, \mathrm{p}=0.03$; species

206 x foraging bout: est $=0.002, \mathrm{z}_{595}=0.32, \mathrm{p}=0.75$ ). Foragers of both species discovered the four flowers

207 during their first five foraging bouts, but honey bees were significantly slower to find the third 208 flower that was the closest to the door in the experimental room (Fig.1C; Wilcoxon test; F3: $209 \mathrm{U}=19.5, \mathrm{p}=0.01, \mathrm{p}>0.05$ for all other flowers). Bumblebees and honey bees visited all flowers in 210 more than $92.4 \% \pm 2.5$ of their foraging bouts, although honey bees visited significantly less the 211 third flower (Fig.1D; Wilcoxon test; $F 3$ : $U=83.5$, p=0.01, p>0.05 for all other flowers). 
213 flowers per foraging bout through time (Fig.1E; Poisson GLMM; foraging bout: est=-0.1, z595=214 12.8, p<0.0001). Foragers of both species also gradually decreased their flight duration (Fig.1F;

215 Poisson GLMM; foraging bout: est=-0.01 z595=-29.35, p<0.0001). However, honey bees showed a

216 lower reduction of immediate revisits (Fig.1E; species x foraging bout: est=0.05, $\mathrm{z}_{595}=6.43$, $217 \mathrm{p}<0.0001)$ and spent consequently more time flying in search for the four flowers (Fig.1F; species $218 \mathrm{x}$ foraging bout: est $=0.002, \mathrm{z}_{595}=3.81, \mathrm{p}=0.0001$ ) than bumblebees. As a result, honeybees showed 219 a significantly lower increase of route quality with time (Binomial GLMM; foraging bout: 220 est=0.163, z595=5.720, p<0.0001, species $\mathrm{x}$ foraging bout: est=-0.137, z595=-4.353, p<0.0001; Fig. $2215 \mathrm{~A})$.

All bumblebees and honey bees used a primary route (i.e. most often used flower visitation 223 sequences excluding revisits) by the end of the experiment (Fig.2A, B). The optimal sequence (F1224 F2-F3-F4 or F4-F3-F2-F1) was used as a primary route by $30 \%$ of the bumblebees (3 out of 10) 225 and $80 \%$ of the honeybees (7 out of 10). On average, bumblebees used their primary route in 36.7 $226 \pm 4 \%$ (SE) of their foraging bouts, and honeybees in $33 \pm 5 \%$ (SE) (Fig.2). Foragers of both species 227 first used this route within their 10 first foraging bouts (bumblebees: $7 \pm 1$ bout, honeybees: $8 \pm 1$ 228 bout; Wilcoxon-rank test; $\mathrm{U}=42, \mathrm{p}=0.56)$ and showed a similar increase in route similarity (DET) 229 with time (Binomial GLMM; foraging bout: est=0.223, $\mathrm{z}_{415}=2.493, \mathrm{p}=0.013$; honey bee $\mathrm{x}$ foraging 230 bout: est=0.301, z415=0.782, p=0.4341; Fig. 5A).

231 Thus, in the four-flowers array, all bumblebees and honey bees developed a route between 232 the four flowers. Honey bees were slower to locate all flowers and to reduce their revisits to empty 233 flowers, even though foragers of both species converged towards repeatable efficient routes 234 towards the end of the experiment.

\section{Six-flowers array}

237 To test whether the complexity of the spatial problem had an influence on the routing performances

238 of bees, we compared the flower visitation sequences of bumblebees and honey bees in an array of 239 six flowers (Fig.3A).Bumblebees and honey bees increased the number of different flowers visited 240 per foraging bout as they gained experience with the array (Fig.3B; Poisson GLMM; foraging bout: $241 \mathrm{est}=0.003, \mathrm{z}_{945}=2.16, \mathrm{p}=0.03$; species $\mathrm{x}$ foraging bout: est=-0.001, $\mathrm{z} 945=-0.52, \mathrm{p}=0.6$ ). However, 242 honey bees visited significantly less flowers per foraging bout (Fig.3B; species: est=-0.18, z945=- 
243 2.97, $\mathrm{p}=0.003)$. Honey bees also took significantly more foraging bouts to discover all flowers 244 (honey bees: $19 \pm 5.7$ (SE) foraging bouts; bumblebees: $4 \pm 1.2$ (SE) foraging bouts) (Fig.3C). The

245 flowers that were the farthest from the hive (flowers 2 and 4) were discovered significantly later 246 by honey bees (Fig.3C; Wilcoxon test; $F 2$ : $U=22.5$, p=0.04; F4: $U=16, p=0.02 ; p>0.05$ for all other 247 flowers). Moreover, all flowers, except flower 5, were visited in fewer foraging bouts by honey 248 bees than by bumblebees (Fig.3D; Wilcoxon test; $F 1$ : U=71.5, p=0.03; F2: U=84, p=0.001; F3: $\mathrm{U}=80.5, \mathrm{p}=0.002 ; F 4: \mathrm{U}=80.5, \mathrm{p}=0.004 ; F 5: \mathrm{U}=66, \mathrm{p}=0.08 ; F 6: \mathrm{U}=76, \mathrm{p}=0.01)$.

Bumblebees and honey bees similarly decreased their number of immediate revisits to 251 flowers with experience (Fig.3E; Poisson GLMM; foraging bout: est=-0.03, z945=-12.8, p<0.0001; 252 species $\mathrm{x}$ foraging bout: est=0.006, $\left.\mathrm{z}_{945}=1.88, \mathrm{p}=0.06\right)$. Foragers of both species gradually 253 decreased their flight duration (Fig.3F; Poisson GLMM; foraging bout: est=-0.006, z945=-29.26, $254 \mathrm{p}<0.0001)$. However, once again, honey bees spent significantly more time flying than bumblebees 255 (Fig.3F; species: est=0.26, $\mathrm{z}_{945}=2.6, \mathrm{p}=0.01$; species $\mathrm{x}$ foraging bout: est=-0.005, $\mathrm{z}_{945}=-16.63$, 256 $\mathrm{p}<0.0001$ ). Thus overall, honey bees showed a lower increase in route quality with time (Binomial GLMM; foraging bout: est=0.064, $\mathrm{z}_{945}=7.953$, p<0.0001; species $\mathrm{x}$ foraging bout: est=-0.043, $\mathrm{Z}_{945}=-3.087$, p=0.002; Fig. 5B).

All bumblebees developed a primary route between the six flowers $(n=10 ;$ Fig.4A $)$. On average, bumblebees used it in $14 \pm 2 \%$ (SE) of their foraging bouts, which is higher than expected by chance (binomial test, $\mathrm{p}<0.0001)$. The optimal route $(\mathrm{F} 1-\mathrm{F} 2-\mathrm{F} 3-\mathrm{F} 4-\mathrm{F} 5-\mathrm{F} 6)$ was used as primary route by $40 \%$ of the bumblebees ( 4 out of 10 individuals). By contrast, only two honey bees developed a primary route between the six flowers and they used it in $12 \pm 2 \%$ (SE) of their foraging 264 bouts. The seven remaining honey bees only developed primary routes between five flowers $(n=4)$, four flowers $(n=2)$, or three flowers $(n=1$; Fig.4B). Irrespective of the number of flowers visited, both species showed a similar increase in route similarity (DET) over successive foraging bouts (Binomial GLMM; foraging bout: est=0.265, $\mathrm{z} 774=2.817, \mathrm{p}=0.005$; honey bee $\mathrm{x}$ foraging bout: est=4.583e+01, z774=0.000, p=1.000; Fig. 5B).

Thus, foragers of both species increased their foraging efficiency with experience.

270 However, while bumblebees developed a route between the six flowers, honey bees hardly found 271 all flowers and used routes between less flowers. 
274 To test whether the model of trapline formation proposed in previous studies (Lihoreau et al. 2012b;

275 Reynolds et al. 2013) could explain the observed differences in routing behaviour between 276 bumblebees and honey bees, we compared observed flower visitation sequences to simulated 277 flower visitation sequences, using route quality and route similarity (DET). In each case, we 278 compared the binomial fit of the experimental data to that of the simulations with different values 279 of learning factor (Lf), and rejected all models that showed a significant difference, ultimately 280 providing a set of $\mathrm{Lf}$ relevant for each species. The results are summarized in Table 1 (comparisons of slopes) and Table S2 (comparisons of intercepts).

We first compared observational and simulated data in the four-flowers array. For bumblebees, the increase of route quality was replicated with Lf ranging from 1.3 to 1.7 (Fig.5A; Table 1) and the increase in route similarity (DET) with Lf ranging from 1.1 to 1.2 (Fig.5B; Table 1). For honey bees, the increase of route quality was replicated with Ln ranging from 1.1 to 1.5 (Fig.5A; Table 1) and the increase of route similarity with Ln ranging from 1.0 to 1.2 (Fig.5B;

Table 1). Results followed a similar pattern in the six-flowers array. For bumblebees, the increase of route quality was replicated with $\operatorname{Lf} 1.5,1.6,1.7$ and 1.9 (Fig.5C; Table 1) and the increase of route similarity with Lf ranging from 1.1 to 1.6, and 1.8 and 2.0. (Fig.5D; Table 1). For honey bees, route quality was replicated with a Lf ranging from 1.3 to 1.5 (Fig.5C; Table 1) and route similarity with a Lf ranging from 1.0 to 1.3 and 1.5 (Fig.5D; Table 1). Similar observations were made by comparing the intercepts of experimental data and models (Table S2). Thus overall, the behaviour of honey bees was replicated with lower values of If than that of bumblebees in both arrays of flowers. This indicates that honey bees were generally slower to develop a route and that their routes were also less efficient.

\section{Discussion}

298 We compared the routing behaviour of two naturally co-occurring generalist pollinators foraging 299 in the same arrays of artificial flowers. While bumblebees and honey bees established routes 300 between four flowers, only bumblebees did so between six flowers. In these conditions, honey bees 301 took a longer time to discover all the flowers and never integrated them all in a single stable 302 visitation sequence.

303 Many animals develop foraging routes (or traplines) to efficiently exploit multiple familiar

304 feeding sites that replenish over time (Janzen 1971; Thomson et al. 1997; Buatois and Lihoreau 

experiments on trapline foraging have been designed to test whether animals could optimise overall travel distances and to explore the cognitive mechanisms involved in route formation (Ohashi and Thomson 2009; Lihoreau et al. 2013). However, comparing these behaviours across individuals and species can bring important insights into the evolution of spatial cognition and its impact on pollination. Recently, Klein et al. (2017) compared the spatial patterns of bumblebee foragers in different arrays of flowers, showing consistent inter-individual variations in speed and efficiency

312 for route development. Here we adopted a similar strategy to compare the routing behaviour of 313 bumblebees and honey bees, and demonstrated that honey bees are generally slower in developing 314 routes, and that their routes are less efficient than those of bumblebees. This result is consistent 315 with indirect comparisons of semi field data (Pasquaretta et al. 2017). Importantly, this key 316 behavioural difference between honey bees and bumblebees was well-captured by changing a 317 single parameter value (the learning factor) in simulations of a previously proposed model of 318 trapline formation (Lihoreau et al. 2012b, Reynolds et al. 2013). Overall, the behaviour of honey bees was best-replicated with lower learning factors than that of bumblebees.

Why do honey bees and bumblebees do not behave the same? The two species greatly differ in social organization and it is possible that their behavioural strategies are influenced by social constraints. Honey bees use the waggle dance to recruit foragers on profitable sites (von Frisch

323 1967) and may thus invest less in individual sampling and learning than bumblebees that do not 324 exhibit dance communication (Dornhaus and Chittka 1999). At the collective level, unperfect 325 traplining and dance communication may be more efficient in tropical environments dominated by 326 densely aggregated resources such as blooming trees where honey bees are expected to originate 327 (Dyer and Seeley 1989), whereas perfect traplining may be an efficienct strategy to maximize 328 collective foraging in environments dominated by spatially distributed resources such as small 329 flower patches. The size of colonies are also dramatically different in the two species. While a 330 honey bee colony can contain thousands of workers, a bumblebee colony only contains hundreds.

331 The foraging workforce of honey bees is therefore highly superior, resulting in a potentially more 332 intense activity of exploration to find new resources and exploit them rapidly, than individual 333 learning to monopolize specific resources for long period of times. Recent studies indicate that 334 honey bee foragers are less accurate than bumblebee foragers in many aspects of foraging, for 335 instance when selecting pollen of different qualities (Leonhard and Bluthgen 2012) or searching 
336 for a target in an arena (Morawetz and Spaethe 2012). Our results are consistent with these 337 observations since, even in the most complex array of six flowers, bumblebees managed to find 338 every flower, while honey bees never visited them all during the same foraging bout.

339 These different spatial behaviours between honey bees and bumblebees may also result 340 from differences in bio-energetics. In addition to an obvious difference of body size, foragers of 341 the two species have a very different nectar crop capacities. While it is well accepted that the usual 342 crop capacity of honey bees is about $60 \mu \mathrm{L}$ (Nunez 1966), the crop of bumblebees is typically 343 around $120 \mu \mathrm{L}$ (Lihoreau et al. 2010,2012a,b). In contrast to bumblebees that often return home 344 with a full crop, honey bees often abandon non-depleting food sources with a partially filled crop 345 (Schmid-Hempel et al. 1985). This behaviour does not maximize the net rate of energy extraction 346 from the food sources but appears to maximize energetic efficiency (net energetic gain/unit energy 347 expenditure) (Schmid-Hempel et al. 1985). This may explain why honey bees in the six-flowers 348 array rarely visited all flowers during a given foraging bout. Note however that honey bees tested 349 both on the four- and six-flowers arrays did significantly more immediate revisits to empty flowers 350 than bumblebees, as well as flew significantly longer, suggesting that they were searching for 351 additional food. It remains relatively unclear why bumblebees have a crop capacity way more 352 stable than honeybees during a foraging flight. Different studies have shown that metabolic rates 353 tested in bumblebees and honey bees during flight were not so different (Kammer and Heinrich 354 1974, Heinrich 1975a,b, Schaffer et al. 1979, Harrison and Fewell 2002, Darveau et al. 2014). 355 Consequently, the flight energy could not be an explanation for the differences observed during 356 our experiments. In addition to potential physical constraints, it is more likely that the difference 357 regarding the crop capacity is triggered by the difference in colony size, as well as the number of 358 recruited foragers for both species. Indeed, the low number of foragers in bumblebees, as well as a 359 poor communication about food, have to be balanced by an optimal individual foraging and 360 therefore a fully filled crop to ensure a maximal transport of ressources. However, in honeybees, 361 with a very large number of foragers, as well as a very sophisticated system of recruitment, the 362 individual foraging does not have to be as efficient since other bees will come to help foraging the 363 resources.

364 The morphological differences between the two species are also accompanied with size 365 differences in sensory organs and brains that could influence routing behaviour. For instance, the 366 bumblebee eye surface is 2 times larger (Streinzer et al. 2013, Streinzer and Spaethe 2014) and its 
367 resolution is about $25 \%$ better than that of the honey bee eye (Macuda et al. 2001). Consequently, 368 bumblebees are more likely to identify a small object at a long distance. In our experiments, 369 although artificial flowers were designed to be detectable by both bumblebees and honey bees, 370 differences in visual acuity may explain why bumblebees were more efficient at finding all flowers.

371 Beyond visual perception, honey bees and bumblebees can notoriously perform a rich diversity of 372 elemental and non-elemental learning tasks (Giurfa 2013, Perry et al. 2017). Despite these 373 elaborated cognitive abilities in both species, the different body size of the two insects also comes 374 with an obvious difference of brain size (Mares et al. 2005). Although it is still quite debated 375 (Chittka and Niven 2009, Lihoreau et al. 2012c), some studies conducted in different species has 376 shown that a larger brains could be associated with better cognitive performances (Buechel et al. 377 2018; Herculano-Houzel 2017). For instance, when tested on the same learning task, large-brained 378 females guppy performed better than the small-brain females (Kotrschal et al. 2013). Such 379 observations have also been performed in bees and allowed to highlight correlation between brain 380 size and some specific behaviour. Sayol et al. (2020) showed an association between larger brain 381 could be associated with ecologically specialized bee species when compared with generalist or 382 multi-generation species. More recently, this question has been explored by comparing 32 different 383 bee species brain size after a colour discrimination task. Regardless of the species, bees with a 384 larger brain were more likely to learn the association between the reward and the colour (Collado 385 et al. 2020). It is therefore reasonable to hypothesise that with a larger brain, bumblebees would be 386 cognitively more efficient, explaining their best performance in our experiments.

Our study focused on route development by bees at small spatial scales in the lab. Although 389 spatial scales, where feeding sites are visually isolated from each other and the cost of flying long 390 suboptimal routes is magnified (Lihoreau et al. 2012b, Buatois and Lihoreau 2016; Woodgate et 391 al. 2017). Future studies should therefore explore whether the differences between bumblebees and 392 honey bees are maintained at larger spatial scales. Honey bees and bumblebees can fly to up to ca. $39310 \mathrm{kms}$ (Goulson and Stout 2001; Pahl et al. 2011). In the field, the difference in relative energetic 394 cost of flight in the two species, due body size differences, may lead honey bees to invest more in 395 route optimization between distant feeding sites. Ultimately, a more systematic analysis and 396 comparisons of the spatial behaviours of key pollinators will help clarify their impact on pollen 
transfer and potential complementarity or redundancy for plant reproduction and crop yield

398 (Garibaldi et al. 2016).

\section{Acknowledgements}

401 This work was funded by the CNRS and three grants from the Agence Nationale de la Recherche 402 to ML (ANR-16-CE02-0002-01; ANR-19-CE37-0024; ANR-20-ERC8-0004-01). While writing, $403 \mathrm{AB}$ was funded by Fyssen. TD was funded by a co-tutelle PhD grant of the University Paul Sabatier

404 (Toulouse) and Macquarie University (Sydney).

405

\section{References}

407 Alem S, Perry CJ, Zhu X, Loukola OJ, Ingraham T, Søvik E, Chittka L. 2016. Associative 408 mechanisms allow for social learning and cultural transmission of string pulling in an insect. PLoS 409 Biol. 14:e1002564.

410 Ayers CA, Armsworth PR, Brosi BJ. 2015. Determinism as a statistical metric for ecologically 411 important recurrent behaviors with trapline foraging as a case study. Behav. Ecol. Sociobiol. 69: 412 1395-1404.

413 Bates D, Maechler M, Bolker B, Walker S. 2015. Fitting linear mixed-effects models using lme4. 414 J. Stat. Soft. 67:1-48.

415 Buechel SD, Boussard A, Kotrschal A, van der Bijl W, Kolm N. 2018. Brain size affects 416 performance in a reversal-learning test. Proc. Royal. Soc. B. 285: 20172031.

417 Buatois A, Lihoreau M. 2016. Evidence of trapline foraging in honeybees. J. Exp. Biol. 219:24264182429.

419 Chittka L. 2017. Bee cognition. Curr. Biol. 27: R1049-R1053.

420 Chittka L, Rossiter SJ, Skorupski P, Fernando C. 2012. What is comparable in comparative 421 cognition? Philos. Trans. R. Soc. Lond. B, Biol. Sci. 367:2677-2685.

422 Chittka L, Niven J. 2009. Are bigger brains better? Curr. Boil. 19:R995-R1008. 
423 Collado MÁ, Montaner CM, Molina FP, Sol D, Bartomeus I. 2020. Brain size predicts learning 424 abilities in bees. BioRxiv.

425 Darveau CA, Billardon F, Bélanger K. 2014. Intraspecific variation in flight metabolic rate in the 426 bumblebee Bombus impatiens: repeatability and functional determinants in workers and drones. J. 427 Exp. Biol. 217:536-544.

428 Deisig N, Lachnit H, Giurfa M, Hellstern F. 2001. Configural olfactory learning in honeybees: 429 negative and positive patterning discrimination. Learn. Mem., 8:70-78.

430 Dornhaus A, Chittka L. 1999. Evolutionary origins of bee dances. Nature, 401:38-38.

431 Dyer AG, Spaethe J, Prack S. 2008. Comparative psychophysics of bumblebee and honeybee 432 colour discrimination and object detection. J. Comp. Physiol. A. 194:617.

433 Dyer FC, Seeley TD. 1989. On the evolution of the dance language. Am. Nat. 133:580-590.

434 Farris SM. 2016. Insect societies and the social brain. Curr. Opin. Insect. Sci. 15:1-8.

435 Garibaldi LA, Carvalheiro LG, Vaissière BE, Gemmill-Herren B, Hipólito J, Freitas, et al. 2016. 436 Mutually beneficial pollinator diversity and crop yield outcomes in small and large 437 farms. Science, 351:388-391.

438 Garibaldi LA, Steffan-Dewenter I, Winfree R, Aizen MA, Bommarco R, Cunningham SA, et al. 439 2013. Wild pollinators enhance fruit set of crops regardless of honey bee 440 abundance. Science, 339:1608-1611.

441 Gilbert LE, Singer MC. 1975. Butterfly ecology. Annu. Rev. Ecol. Evol. Syst. 365-397.

442 Giurfa M, Núñez JA. 1992. Honeybees mark with scent and reject recently visited 443 flowers. Oecologia, 89:113-117.

444 Giurfa M, Vorobyev M, Kevan P, Menzel R. 1996. Detection of coloured stimuli by honeybees: 445 minimum visual angles and receptor specific contrasts. J. Comp. Physiol. A. 178:699-709.

446 Giurfa M, Vorobyev M, Brandt R, Posner B, Menzel R. 1997. Discrimination of coloured stimuli 447 by honeybees: alternative use of achromatic and chromatic signals. J. Comp. Physiol. A. 180:235448243. 
449 Giurfa M, Zhang S, Jenett A, Menzel R, Srinivasan MV. 2001. The concepts of 'sameness' and 450 'difference' in an insect. Nature, 410:930-933.

451 Giurfa M. 2013. Cognition with few neurons: higher-order learning in insects. Trends. Neurosci. $452 \quad 36: 285-294$.

453 Goulson D, Stout JC. 2001. Homing ability of the bumblebee Bombus terrestris (Hymenoptera: 454 Apidae). Apidologie. 32:105-111.

455 Harrison JF, Fewell J H. 2002. Environmental and genetic influences on flight metabolic rate in 456 the honey bee, Apis mellifera. Comp. Biochem. Physiol. Part A. Mol. Integr. Physiol. 133:323457333.

458 Heinrich B. 1975a. Thermoregulation in bumblebees. J. Comp. Physiol. 96:155-166.

459 Heinrich B. 1975b. Energetics of pollination. Annu. Rev. Ecol. Evol. Syst., 6:139-170.

460 Herculano-Houzel S. 2017. Numbers of neurons as biological correlates of cognitive 461 capability. Curr. Opin. Behav. Sci. 16:1-7.

462 Janzen DH. 1971. Euglossine bees as long-distance pollinators of tropical plants. Science. 171:203463205.

464 Kammer AE, Heinrich B. 1974. Metabolic rates related to muscle activity in bumblebees. J. Exp. 465 Biol. 61:219-227.

466 Kapustjansky A, Chittka L, Spaethe J. 2010. Bees use three-dimensional information to improve 467 target detection. Naturwissenschaften, 97:229-233.

468 Kotrschal A, Rogell B, Bundsen A, Svensson B, Zajitschek S, Brännström I, et al. 2013. Artificial 469 selection on relative brain size in the guppy reveals costs and benefits of evolving a larger brain. 470 Curr. Biol. 23:168-171.

471 Klein S, Pasquaretta C, Barron AB, Devaud JM, Lihoreau M. 2017. Inter-individual variability in 472 the foraging behaviour of traplining bumblebees. Sci. Rep.. 7:4561.

473 Leonhardt SD, Blüthgen N. 2012. The same, but different: pollen foraging in honeybee and 474 bumblebee colonies. Apidologie. 43:449-464. 
475 Lemke TO. 1984. Foraging ecology of the long-nosed bat, Glossophaga soricina, with respect to 476 resource availability. Ecology, 65:538-548.

477 Lihoreau M, Raine NE, Reynolds AM, Stelzer RJ, Lim KS, Smith AD, et al. 2013. Unravelling the 478 mechanisms of trapline foraging in bees. Commun. Integr. Biol. 6:e1001392.

479 Lihoreau M, Chittka L, Le Comber SC, Raine NE. 2012a. Bees do not use nearest-neighbour rules 480 for optimization of multi-location routes. Biol. Lett. 8:13-16.

481 Lihoreau M, Raine NE, Reynolds AM, Stelzer RJ, Lim KS, Smith AD, et al. 2012b. Radar tracking 482 and motion-sensitive cameras on flowers reveal the development of pollinator multi-destination 483 routes over large spatial scales. PLoS Biol, 10:e1001392.

484 Lihoreau M, Latty T, Chittka L. 2012c. An exploration of the social brain hypothesis in insects. 485 Front. Physiol. 3:442.

486 Lihoreau M, Chittka L, Raine NE. 2010. Travel optimization by foraging bumblebees through 487 readjustments of traplines after discovery of new feeding locations. Am. Nat, 176:744-757.

488 Macuda T, Gegear R, Laverty T, Timney B. 2001. Behavioural assessment of visual acuity in 489 bumblebees (Bombus impatiens). J. Exp. Biol., 204:559-564.

490 Mares S, Ash L, Gronenberg W. 2005. Brain allometry in bumblebee and honey bee 491 workers. Brain. Behav. Evol. 66:50-61.

492 Morawetz L, Spaethe J. 2012. Visual attention in a complex search task differs between honeybees 493 and bumblebees. J. Exp. Biol., 215:2515-2523.

494 Núñez JA. 1966. Quantitative beziehungen zwischen den eigenschaften von futterquellen und dem 495 verhalten von sammelbienen. J. Comp. Physiol., 53:142-164.

496 Ohashi K, Thomson JD. 2009. Trapline foraging by pollinators: its ontogeny, economics and 497 possible consequences for plants. Ann. Bot. 103:1365-1378.

498 Ohashi, K., Thomson, J. D., \& D'souza, D. (2007). Trapline foraging by bumble bees: IV. 499 Optimization of route geometry in the absence of competition. Behavioral Ecology, 18(1), 1-11.

500 Ohashi, K., \& Thomson, J. D. (2005). Efficient harvesting of renewing resources. Behavioral 501 Ecology, 16(3), 592-605. 
Pahl M, Zhu H, Tautz J, Zhang S. 2011. Large scale homing in honeybees. PLoS One. 6:e19669.

503 Perry CJ, Barron AB, Chittka L. 2017. The frontiers of insect cognition. Curr. Opin. Behav. Sci.

504 16:111-118.

505 Pasquaretta C, Jeanson R, Andalo C, Chittka L, Lihoreau M. 2017. Analysing plant-pollinator 506 interactions with spatial movement networks. Ecol. Entomol. 42:4-17.

507 Pearce RF, Giuggioli L, Rands SA. 2017. Bumblebees can discriminate between scent-marks 508 deposited by conspecifics. Sci. Rep. 7:43872.

509 Possingham HP. 1989. The distribution and abundance of resources encountered by a forager. Am.

$510 \quad$ Nat. 133:42-60.

511 Reynolds AM, Lihoreau M, Chittka L. 2013. A simple iterative model accurately captures complex 512 trapline formation by bumblebees across spatial scales and flower arrangements. PLoS. Comput. 513 Biol. 9:e1002938.

514 Sayol F, Collado MÁ, Garcia-Porta J, Seid MA, Gibbs J, Agorreta A, et al. 2020. Feeding 515 specialization and longer generation time are associated with relatively larger brains in bees. Proc. 516 Royal Soc. B. 287:20200762.

517 Schmid-Hempel P, Kacelnik A, Houston AI. 1985. Honeybees maximize efficiency by not filling 518 their crop. Behav. Ecol. Sociobiol. 17:61-66.

519 Schaffer WM, Jensen DB, Hobbs DE, Gurevitch J, Todd JR, Schaffer MV. 1979. Competition, 520 foraging energetics, and the cost of sociality in three species of bees. Ecology, 60:976-987.

521 Srinivasan MV, Lehrer M. 1988. Spatial acuity of honeybee vision and its spectral properties. J. 522 Comp. Physiol. A. 162:159-172.

523 Streinzer M, Brockmann A, Nagaraja N, Spaethe J. 2013. Sex and caste-specific variation in 524 compound eye morphology of five honeybee species. PLoS One. 8:e57702.

525 Streinzer M, Spaethe J. 2014. Functional morphology of the visual system and mating strategies in 526 bumblebees (Hymenoptera, Apidae, Bombus). Zool. J. Linn. Soc. 170:735-747.

527 Taiwanica Z. 2000. ETHOM: event-recording computer software for the study of animal 528 behavior. Acta Zool. Taiwanica. 11:47-61. 
529 Team RC. 2016. R: a language and environment for statistical computing. R Development Core

530 Team, Vienna.

531 Tello-Ramos MC, Hurly TA, Healy SD. 2015. Traplining in hummingbirds: flying short-distance

532 sequences among several locations. Behav. Ecol. 26:812-819.

533 Thomson JD, Slatkin M, Thomson BA. 1997. Trapline foraging by bumble bees: II. Definition and

534 detection from sequence data. Behav. Ecol. 8:199-210.

535 Thomson JD. 1996. Trapline foraging by bumblebees: I. Persistence of flight-path 536 geometry. Behav. Ecol. 7:158-164.

537 Traniello IM, Chen Z, Bagchi VA, Robinson GE. 2019. Valence of social information is encoded 538 in different subpopulations of mushroom body Kenyon cells in the honeybee brain. Proc. Royal 539 Soc. B. 286:20190901.

540 Von Frisch K. 1967. The dance language and orientation of bees. Harvard University Press.

541 Woodgate JL, Makinson JC, Lim KS, Reynolds AM, Chittka L. 2017. Continuous radar tracking

542 illustrates the development of multi-destination routes of bumblebees. Sci. Rep. 7:1-15.

543 Wooller RD, Richardson KC, Bradley GO. 1999. Dietary constraints upon reproduction in an 544 obligate pollen-and nectar-feeding marsupial, the honey possum (Tarsipes rostratus). J. Zool. $545 \quad 248: 279-287$. 


\section{$548 \quad$ Figures and figure legends}

\section{Figure 1}

550
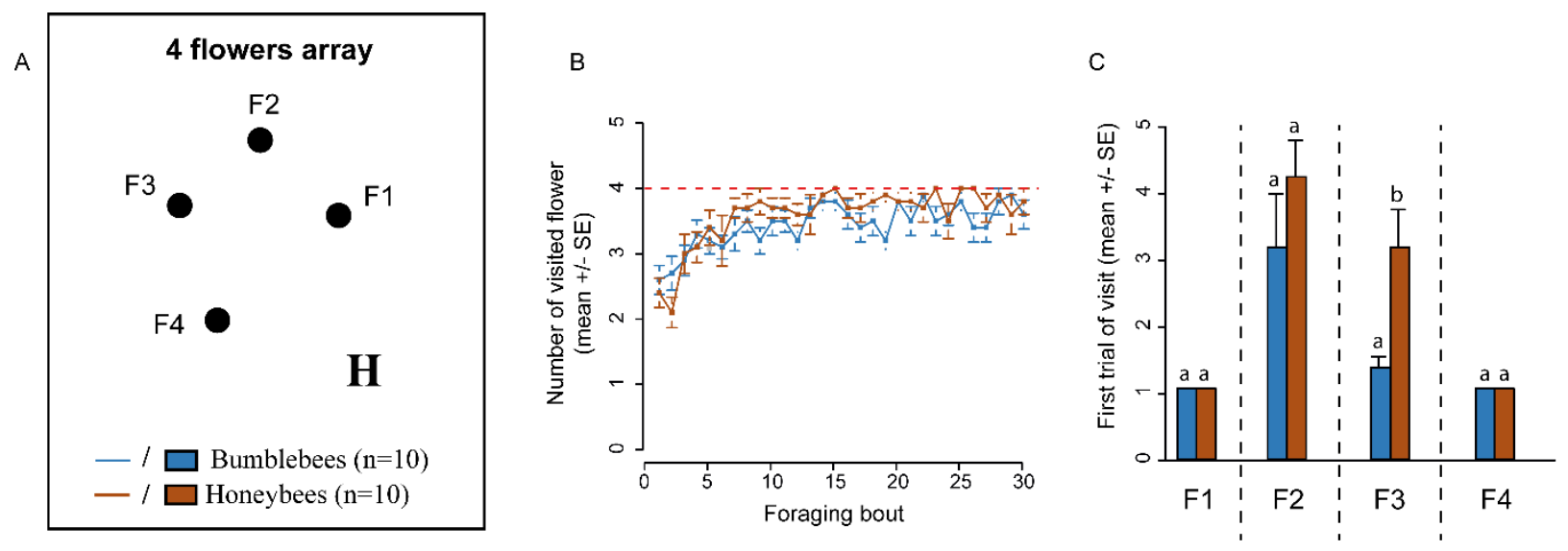

$\mathrm{D}$
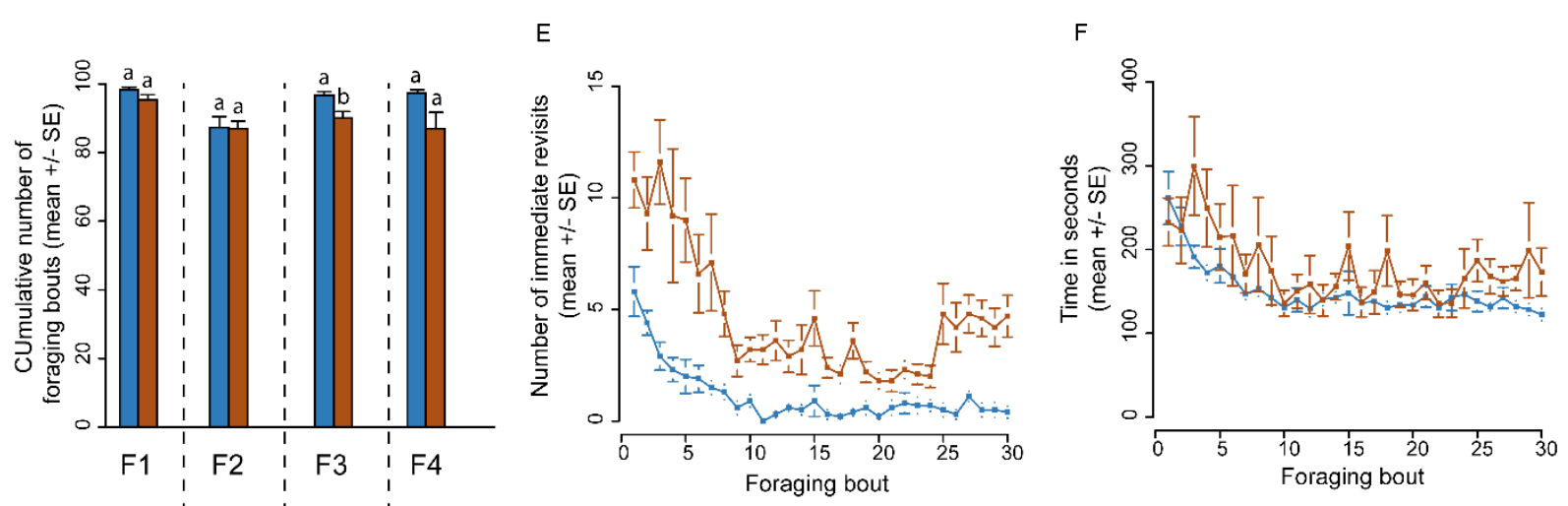

552 Figure 1: Route formation in the four-flowers array. (A) Schematic representation of the flower 553 array. Flowers are labelled F1-F4. H is the colony hive location. (B) Number of flowers visited per 554 foraging bout. (C) Cumulated number of foraging bouts before the flower was first visited. (D) 555 Percentage of foraging bouts for which each flower was visited. (E) Number of immediate revisits 556 to flowers per foraging bout. (F) Flight duration per foraging bout. The mean \pm standard error is 557 presented for each graph. Different letters indicate a significant difference in (C) and (D) 558 (Wilcoxon Rank-test for independent data). 


\section{Figure 2}

561

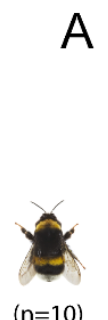

$(n=10)$

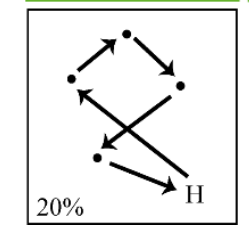

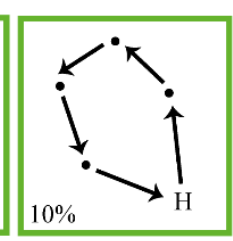

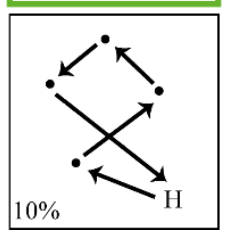

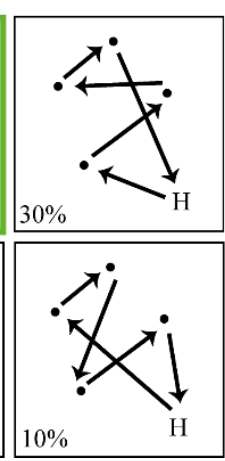
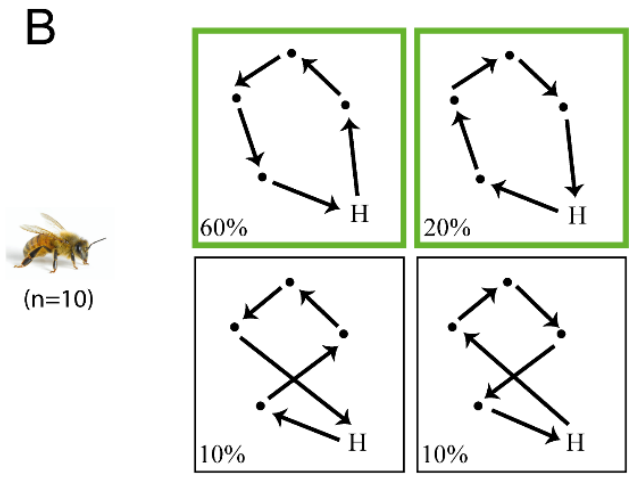

563 Figure 2: Primary routes in the four-flowers array. (A) Primary route used by bumblebees. (B)

564 Primary route used by honeybees (B). Black dots represent flower locations. $\mathrm{H}$ is the colony hive

565 location. Arrows indicate the direction in which the bee moved. The percentage indicates the

566 proportion of bees that used this route pattern. Optimal routes are highlighted in green. 


\section{Figure 3}

569

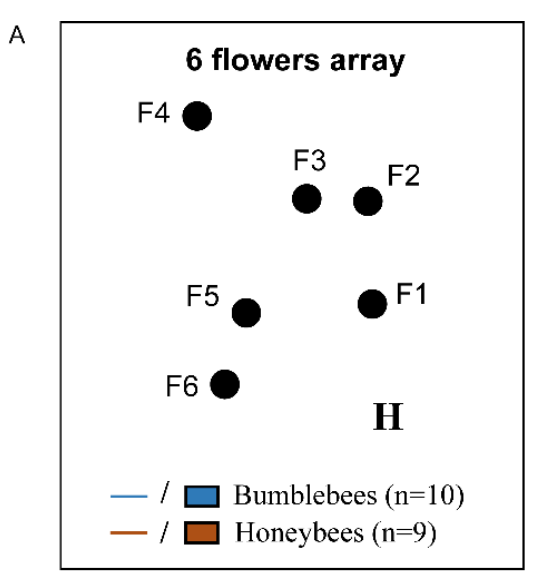

D

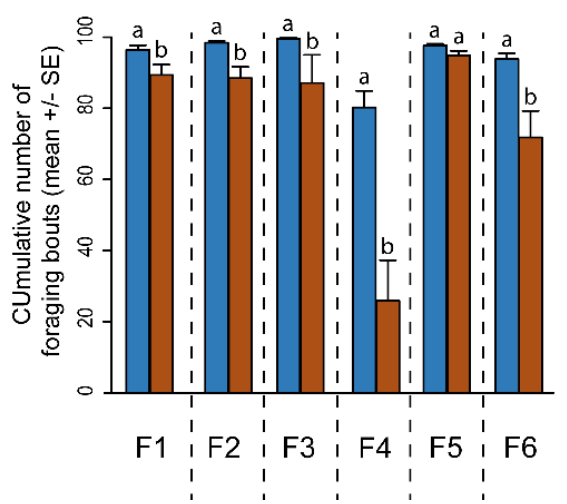

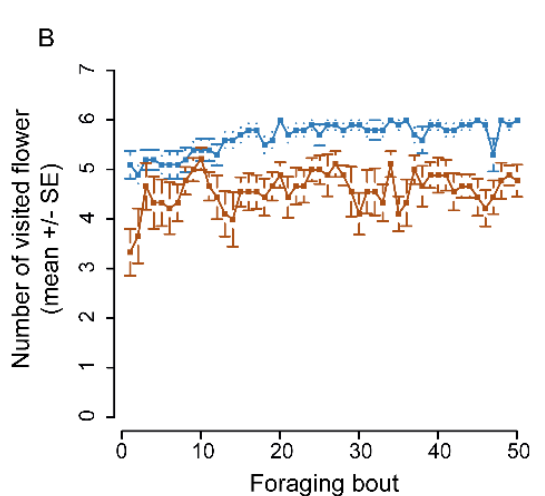

C

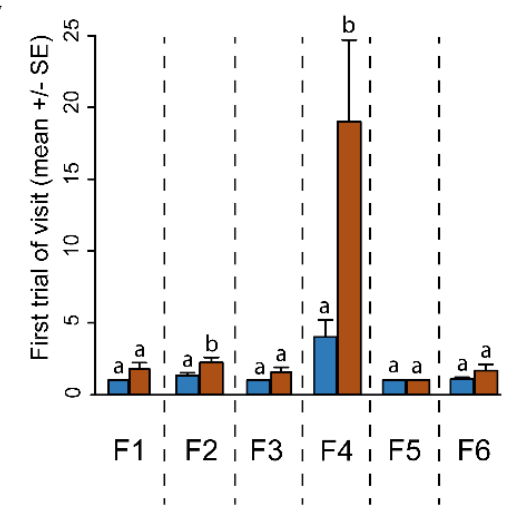

E

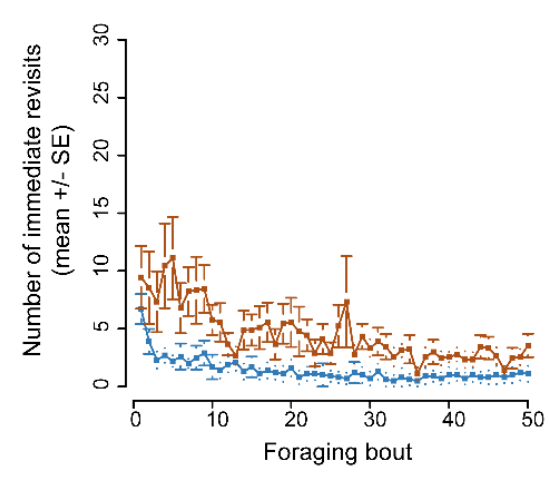

F

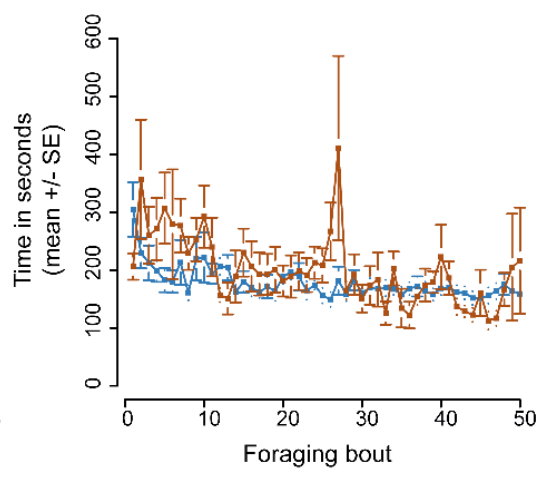

570

571 Figure 3: Route formation in the six-flowers array. (A) Schematic representation of the flower

572 array. Flowers are labelled F1-F6. H is the colony hive location. (B) Number of flowers visited per

573 foraging bouts. (C) Cumulated number of foraging bouts before the flower was first visited (D)

574 Percentage of foraging bouts for which each flower was visited. (E) Number of immediate revisits

575 to flowers per foraging bout. (F) Flight duration per foraging bout. The mean \pm standard error is

576 presented for each graph. Different letters indicate a significant difference in (C) and (D)

577 (Wilcoxon Rank-test for independent data). 


\section{Figure 4}

580

A
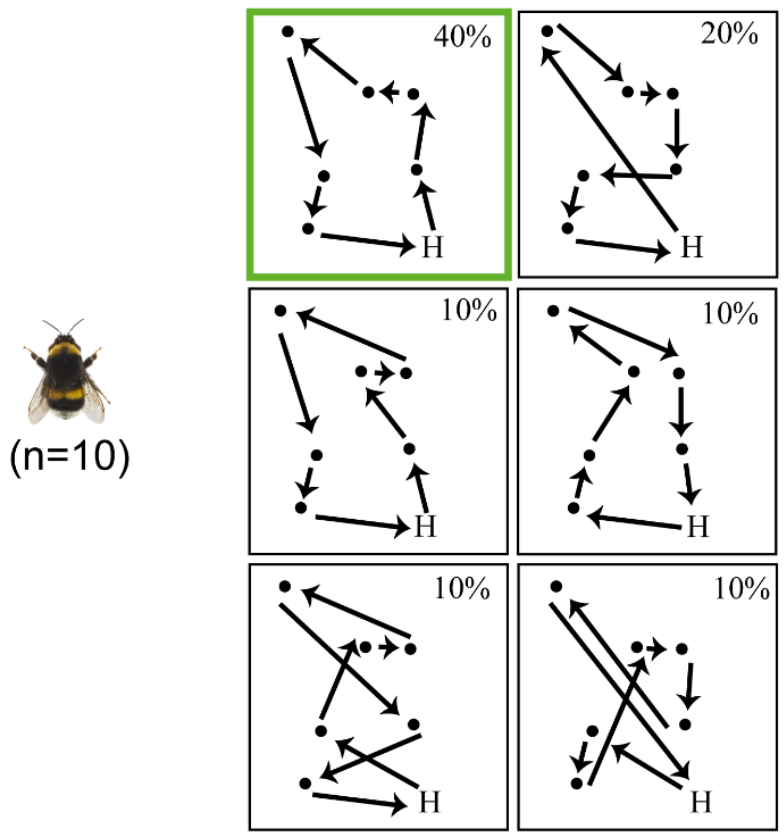

B

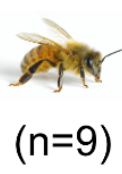

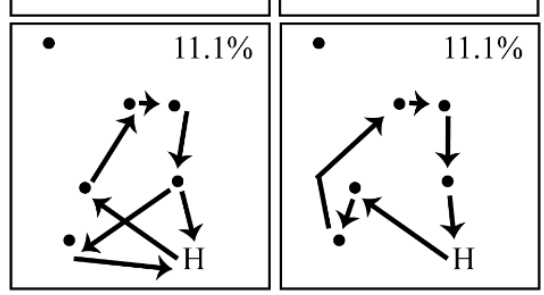
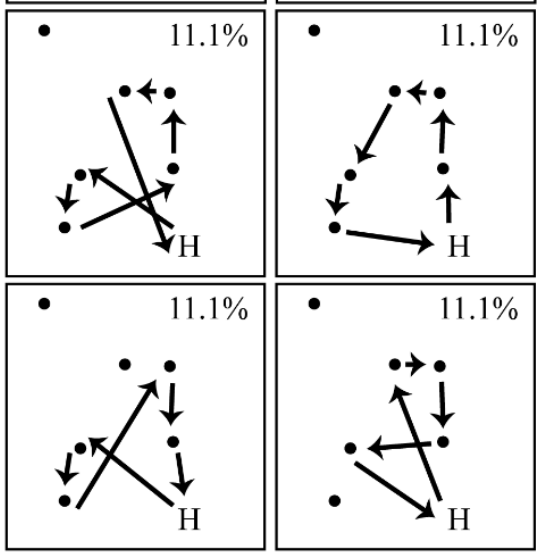

- $11.1 \%$

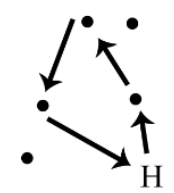

582 Figure 4: Primary routes on the six-flowers assay. (A) Primary route used by bumblebees. (B)

583 Primary route used by honeybees (B). Black dots represent flower locations. $\mathrm{H}$ is the colony hive

584 location. Arrows indicate the direction in which the bee moved. The percentage indicates the 585 proportion of bees that used this route pattern. Optimal routes are highlighted in green. 


\section{Figure 5}

588
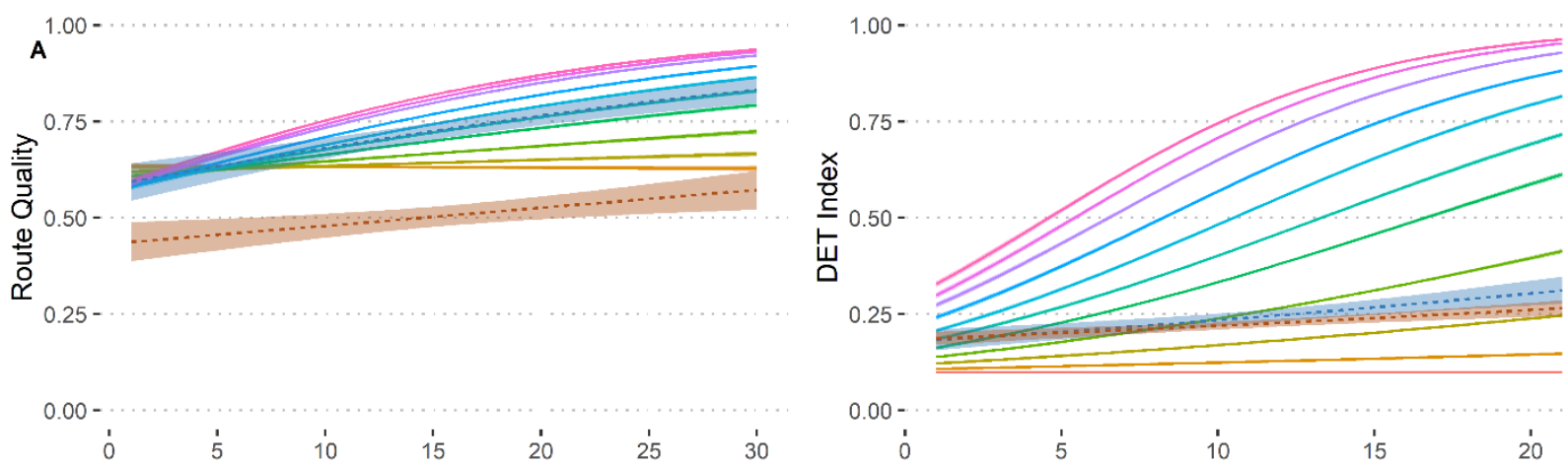

B 1.00
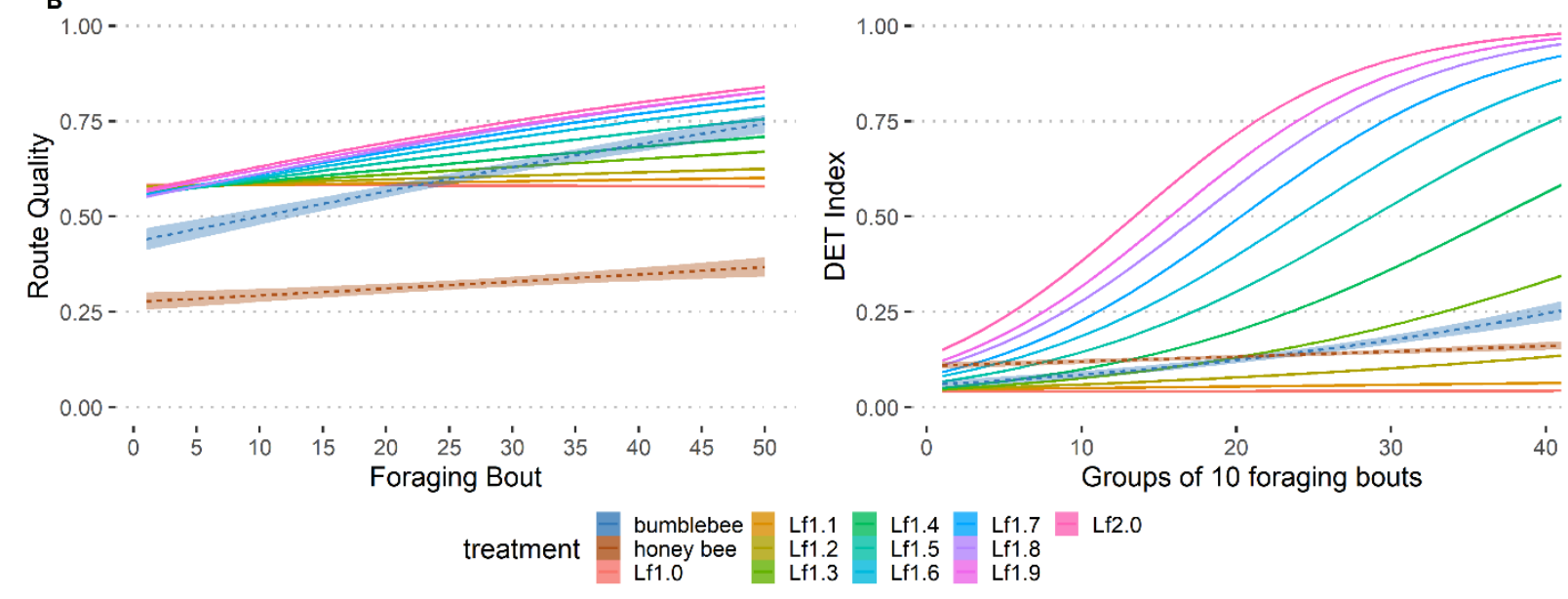

590 Figure 5. Comparison between observed and simulated data. For each batch of model

591 simulations (named after the value of the learning factor Lf) and both species (bumbleblees and

592 honey bees), the route quality and the route similarity (DET) indices are shown. A) Four-flowers

593 array. B) Six-flowers array. N = 1000 simulations per Lf. Means are displayed with standard errors. 


\section{Table}

596

\begin{tabular}{|c|c|c|c|c|c|c|c|c|c|c|c|c|c|}
\hline Array & Variable & Species & Lf1.0 & Lf1.1 & L11.2 & Lf1. 3 & Lf1.4 & L11.5 & Lf1.6 & Lf1.7 & Lf1.8 & Lf1.9 & L 12.0 \\
\hline $4 \mathrm{~F}$ & Quality & Bumblebee & 0.001 & 0.005 & 0.029 & 0.084 & 0.306 & 0.832 & 0.432 & 0.155 & 0.005 & $00 \mathrm{e}-$ & $89 e-1$ \\
\hline $4 \mathrm{~F}$ & Quality & Honey bee & 0.014 & 0.070 & 0.054 & 0.577 & 0.332 & 0.070 & $2.92 \mathrm{e}-0$ & $1.13 \mathrm{e}-0 \mid$ & $3.42 e-12$ & ;.77-e1: & $70 \mathrm{e}-14$ \\
\hline $4 \mathrm{~F}$ & Similarity (DET) & Bumblebee & 0.046 & 0.351 & 0.557 & 0.046 & 0.035 & 0.007 & 04 - & 0.008 & $76-0$ & les. & $6 e$. \\
\hline $4 \mathrm{~F}$ & Similarity (DET) & Honey bee & 0.667 & 0.222 & 0.324 & 0.029 & 0.001 & 0.003 & 0.001 & 0.002 & 1.35e-06 & $1.25 \mathrm{e}-0$. & $22 \mathrm{e}-0$. \\
\hline $6 \mathrm{~F}$ & Quality & Bumblebee & 1.420 & .050 . & 20 & 1.220. & $3.720-$ & 0.154 & 0.743 & 0.154 & 0.018 & 0.059 & \\
\hline $6 \mathrm{~F}$ & Quality & Honey bee & 8.59e-.04 & 0.001 & 0.003 & 0.084 & 0.525 & 0.106 & 0.012 & $3.81 \mathrm{e}-0$. & $1.03 e-08$ & $2.21 \mathrm{e}-0 \mathrm{t}$ & $.25 \mathrm{e}-07$ \\
\hline $6 \mathrm{~F}$ & Similarity (DET) & Bumblebee & 0.007 & 0.339 & 0.978 & 0.064 & 0.052 & 0.343 & 0.225 & 0.040 & 0.077 & 0.033 & 0.064 \\
\hline $6 \mathrm{~F}$ & Similarity (DET) & Honey bee & 0.077 & 0.453 & 0.800 & 0.077 & 0.019 & 0.091 & 0.00 & cye. & $18 \mathrm{e}-0$ & usu & $6 \mathbf{6}$ \\
\hline
\end{tabular}

598 Table 1: Statistical comparison between observed and simulated data. Summary of all the p-

599 values obtained when comparing the models to the experimental data, using the route quality and

600 route similarity (DET Index). The p-values displayed are for the slope comparisons. The color code

601 for p-values is 'green' $<1$; 'yellow' $<0.1$; 'orange' $<0.05$; 'light red' $<0.01$; 'red' $<0.001$.

602

603

604

605

606 